\title{
Transpicuous-Cum-Fouling Resistant Copolymers of 3-Sulfopropyl Methacrylate and Methyl Methacrylate for Optronics Applications in Aquatic Medium and Healthcare
}

\author{
Shehla Mushtaq, ${ }^{1}$ Nasir M. Ahmad $\left(\mathbb{D},{ }^{2}\right.$ Habib Nasir $\mathbb{D}^{1},{ }^{1}$ Azhar Mahmood, ${ }^{1}$ \\ and Hussnain A. Janjua ${ }^{3}$ \\ ${ }^{1}$ Department of Chemistry, School of Natural Sciences (SNS), National University of Sciences and Technology, H-12, \\ Islamabad 44000, Pakistan \\ ${ }^{2}$ Polymer Research Group, School of Chemical and Materials Engineering (SCME), National University of Sciences and Technology, \\ H-12, Islamabad 44000, Pakistan \\ ${ }^{3}$ Department of Industrial Biotechnology, Atta-Ur-Rahman School of Applied Biosciences (ASAB), National University of Sciences \\ and Technology, H-12, Islamabad 44000, Pakistan
}

Correspondence should be addressed to Nasir M. Ahmad; nasir.ahmad@scme.nust.edu.pk

Received 10 July 2020; Accepted 10 September 2020; Published 5 October 2020

Academic Editor: Alexandra Mu oz Bonilla

Copyright ( 92020 Shehla Mushtaq et al. This is an open access article distributed under the Creative Commons Attribution License, which permits unrestricted use, distribution, and reproduction in any medium, provided the original work is properly cited.

\begin{abstract}
The scope of optical sensors and scanners in aquatic media, fluids, and medical diagnostics has been limited by paucity of transparent shielding materials with antifouling potential. In this research endeavor, facile synthesis, characterization, and bioassay of antifouling transparent functional copolymers are reported. Copolymers of 3-sulfopropyl methacrylate (SPMA) and methyl methacrylate (MMA) were synthesized by free radical polymerization in various proportions. Samples PSM20, PSM30, PSM40, PSM50, and PSM60 contain 20\%, 30\%, 40\%, 50\%, and 60\% SPMA by weight, respectively. Resultant products were characterized by FTIR and ${ }^{1} \mathrm{H}-\mathrm{NMR}$ spectroscopy. The synthesized copolymers have exhibited excellent transparency, i.e., $75 \%$ to $88 \%$, as determined by the UV-Vis spectroscopic analysis. Transmittance was decreased from $6 \%$ to $2 \%$ in these copolymers upon changing the concentration of 3-sulfopropyl methacrylate from $20 \%$ to $50 \%$ owing to bacterial and algal biofilm formation. Water contact angle values were ranged from $18^{\circ}$ to $63^{\circ}$ and decreased with the increase in the polarity of copolymers. The surface energy lowest value $58 \mathrm{~mJ} / \mathrm{m}^{2}$ and highest value $72 \mathrm{~mJ} / \mathrm{m}^{2}$ were calculated for PSM20 and PSM50, respectively, by the Chibowski approach and Young equation. Sample PSM50 has exhibited the highest antibacterial activities, i.e., $18 \mathrm{~mm}$ and $19 \mathrm{~mm}$, against Escherichia coli and Staphylococcus aureus, respectively, by the disk diffusion method. Copolymer PSM50 has shown minimum algal adhesion for Dictyosphaerium algae as observed by optical microscopy. This lower bacterial and algal adhesion is attributed to higher concentrations of anionic SPMA monomer that cause electrostatic repulsion between functional groups of the polymer and microorganisms. Thus, the resultant PSM50 product has exhibited good potential for optronics shielding application in aquatic medium and medical diagnostics.
\end{abstract}

\section{Introduction}

Biofouling is an undesirable growth of different types of microorganisms at a material surface that causes various problems including deterioration of polymeric materials, corrosion of metals, and decline in equipment efficiency [1]. Biofouling also damaged input/output signals of sensors and scanners installed in aquatic bodies by increasing opacity of transparent shields. Polymers are synthesized with specific functional groups to combat biofilm formation for a number of applications [2,3]. Antifouling copolymer with a defined ratio between hydrophobic and hydrophilic monomer units is a facile approach to control microbial growth at a commercial scale $[4,5]$. In the field of polymers, two fundamental kinds of materials can be recognized, contingent upon whether the additive is temporarily enclosed within the 
polymer or permanently connected with the chains $[6,7]$. Advances in polymerization techniques have facilitated the development of more complex polymer structures some of which have been investigated as synthetic antifouling polymers $[8,9]$. So far, most of the research has been focused on customizing the composition of copolymer systems, where chemical functionalities are disseminated over the length of a polymer chain [10, 11]. Antifouling polymers are emerging materials for biocidal applications in several critical areas where surface contacts may risk being attacked by bacteria, viruses, and algae [12]. For instance, around $80-95 \%$ of hospital-acquired urinary tract infections originate from urinary catheters [13]. This is even more relevant now taking into account the ongoing COVID-19 situation, where materials and surfaces are susceptible to attachment of harmful species, and thus indicates the importance of the transparent antifouling polymers in healthcare applications. These antifouling polymeric products are broadly used in medical devices, packaging products, and delivery systems for solid and liquid pharmaceuticals [12]. Various techniques have been used for the synthesis of antifouling polymers; among them, free radical polymerization provides a specific approach for modification of polymer and its subsequent applications [14]. Free radical polymerization is a vital technique for the synthesis of macromolecules and consistent with a wide range of functional groups, which are not compatible with metal-catalyzed and ionic polymerization [15]. It is initiated by using several initiators like ammonium persulfate, potassium persulfate, and azobisisobutyronitrile [16]. The most significant and vital factor is the precise temperature range of $20-100^{\circ} \mathrm{C}$ to proceed free radical polymerization in a highly controlled manner as compared to other polymerization techniques due to its exothermic nature [17]. Free radical polymerization is not affected by protic impurities like water and can be performed in bulk [18]. Acrylic monomers are readily synthesized due to ester functional groups and produce a number of polymers with different characteristics $[19,20]$. Former analysis has proposed that these properties of the hydration layer on polymeric chains are very critical to assess the origin of the repulsing force against protein and have significant effects on the degree of protein adsorption [21, 22]. This strong hydration effect leads to strong resistance against fouling organisms [22]. Adherence of fouling organisms is the initial step leading to biofilm formation that reduces the efficiency of the materials with time and causes significant limitations to the endpoint utility of many materials [23]. Monomers with a sulfonated functional group have been reported in a number of biocidal applications through different synthetic approaches such as copolymerization and grafting [3]. Many studies have been taken in this regard among which Ahmed et al., which have done grafting of poly-3-sulfopropyl methacrylate (PSPMA) onto carboxymethyl cellulose (CMC) via free radical polymerization technique, have reported $3.1 \pm 1.2$ antibacterial activity [24]. Oh et al. synthesized brushes of SPMA negatively charged monomers with positively charged and neutral acrylate monomers for deadhesion of bacteria $28 \pm 9 \mathrm{nN} \cdot \mathrm{nm}$ [25]. Mai et al. have synthesized copolymers of SPMA and polyethylene oxide (PEO) to study biofilm inhibition on teeth
$[26,27]$. In previous studies, surface modification and incorporation of nanoparticles were done using 3-sulfopropyl methacrylate monomer, and antifouling properties were studied but not primarily focused on their transparency.

In consideration of the challenges and significance of transparency along with antifouling characteristics, herein, novel copolymers were synthesized by optimizing their transparency and antifouling property. Transparent antifouling copolymers of 3-sulfopropyl methacrylate (SPMA) and methyl methacrylate (MMA) are synthesized by free radical polymerization in the presence of water along with DMF as solvent by changing monomer ratios in copolymers. Antifouling effects and percent transmittance of copolymers were studied by changing compositions of SPMA and MMA monomers as presented in Scheme 1. These copolymers with a low water contact angle and high surface energy have shown good antifouling activity against Gram +/-ve bacteria and microalgae (Dictyosphaerium species). Antibacterial activity against $E$. coli and $S$. aureus has been probed by the disk diffusion method, and further bacterial biofilm has been analyzed by SEM [28]. Algal biofilm for Dictyosphaerium species has been examined by optical microscopy [29]. The results of the current work are significant and provide a facile approach to develop functional antifouling polymers by optimizing transparency for potential applications in various areas including healthcare.

\section{Materials and Methods}

2.1. Materials. All chemicals were of analytical grade and utilized without any further purification or additional treatment. Methyl methacrylate (MMA) (Sigma, USA), 3sulfopropyl methacrylate (SPMA) (Sigma-Aldrich, Germany), azobisisobutyronitrile (AIBN), dimethylformamide (DMF), ethanol, paraformaldehyde (PFA), and $\mathrm{NaOH}$ were acquired from Sigma-Aldrich (Germany). Tryptose broth (TSB) (Merck, Germany), phosphate buffer solution (PBS) (Amresco, Belgium), Mueller-Hinton agar (MHA) (Daejung, Korea), and BG11 medium (Scharlau, Spain) were used for algal growth. For the bioassays, E. coli (ATTC 8739), S. aureus (ATCC 6538), and Dictyosphaerium sp. (microalgae) were used as representative strains. All solutions and suspensions were prepared by distilled water.

2.2. Synthesis of Copolymers. Polymerization of acrylate monomers was accomplished through the free radical polymerization technique in DMF and water at $70^{\circ} \mathrm{C}$ under inert atmosphere by $2,2^{\prime}$-azobisisobutyronitrile (AIBN) as an initiator (Figure 1) [20]. For synthesis of the PSM50 sample, polymerization of SPMA and MMA was performed in DMF: water 60:40 $(v / v)$ medium and with |SPMA|MMA|AIBN| 1:1:0.002 molar ratios. SPMA (1 g, $4.8 \mathrm{mmol})$, MMA (1 g, $9.9 \mathrm{mmol})$, AIBN (0.002 g, $0.0121 \mathrm{mmol})$, DMF $(12 \mathrm{ml})$, and $\mathrm{H}_{2} \mathrm{O}(8 \mathrm{ml})$ were introduced in a three-neck flask. Polymerization was executed under continuous nitrogen gas purging to keep the inert environment in the flask while temperature was maintained at around $70^{\circ} \mathrm{C}$ through oil bath. After polymerization, solvent was removed by a rotary evaporator and the copolymer was dried in a vacuum 


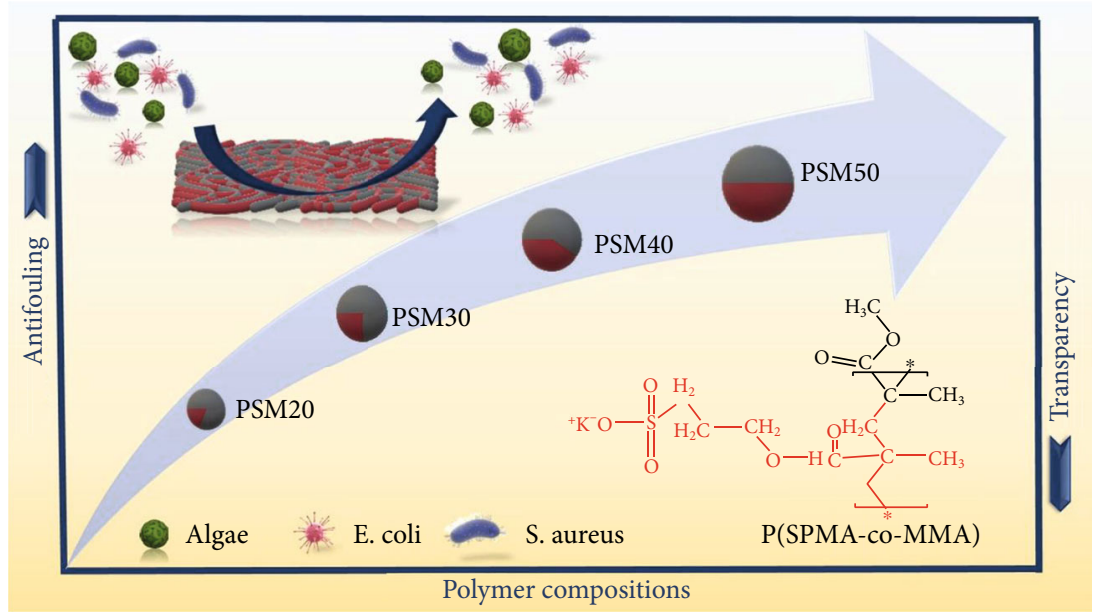

Scheme 1: Overview of synthesized antifouling polymers of P(SPMA-co-MMA) to highlight the influence of antifouling and transparency.

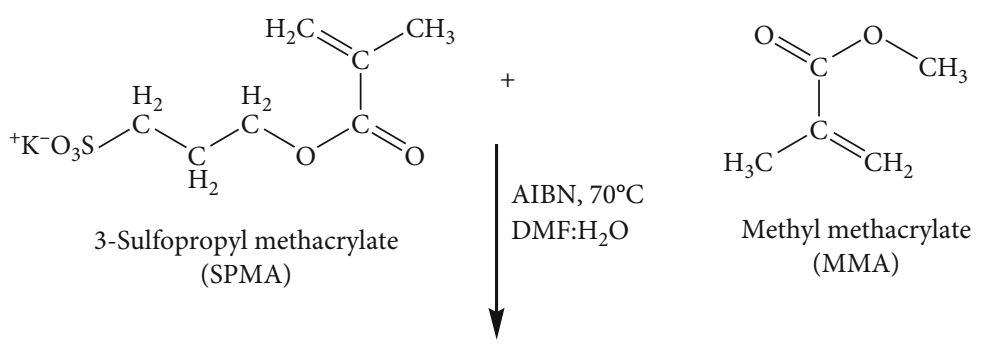<smiles></smiles>

P (SPMA-co-MMA)

Figure 1: Synthesis of copolymers P(SPMA-co-MMA) through polymerization of 3-sulfopropyl methacrylate (SPMA) and methyl methacrylate (MMA).

oven at $600 \mathrm{~mm}$ pressure and $40^{\circ} \mathrm{C}$ temperature in a petri dish. After drying the copolymer, PSM50 was removed from the petri dish in the form of a transparent sheet. For synthesis of different copolymer samples, the above procedure was repeated except that the concentration of SPMA and MMA monomers was changed as tabulated in Table 1.

2.3. Characterization and Bioassay. Fourier Transform Infrared Spectroscopy (FTIR) was performed using the Bruker, ALPHA-P FTIR spectrometer for functional group determination. ${ }^{1} \mathrm{H}-\mathrm{NMR}$ spectra were acquired through the Bruker,
ASCEND $400 \mathrm{MHz}$ NMR spectrometer by dissolving $3 \mathrm{mg}$ sample into $1 \mathrm{ml}$ deuterated DMSO solvent at $343 \mathrm{~K}$ temperature [30]. UV-Visible spectroscopy was performed on JENWAY7315 to analyze transparency of these copolymers and to calculate absorption maxima $\left(\lambda_{\max }\right)$ values due to $\pi-\pi^{*}$ electronic transition of functional groups from SPMA and MMA monomers [31]. The equilibrium water contact angles of sample size $1 \times 1 \mathrm{~cm}^{2}$ were measured by using the drop analyzer of Kruss DSA 25 at room temperature while advancing and receding angles were computed from the average of at least five measurements [32]. Bacterial and algal adhesions 
TABLE 1: Sample codes with concentration of SPMA and MMA.

\begin{tabular}{lcccccc}
\hline \multirow{2}{*}{ Sample codes } & \multicolumn{2}{c}{ Weight (\%) } & \multicolumn{2}{c}{$\begin{array}{c}\text { Concentration } \\
(\mathrm{mmol})\end{array}$} & \multicolumn{2}{c}{ Mol (\%) } \\
& SPMA & MMA & SPMA & MMA & SPMA & MMA \\
\hline PSM60 & 60 & 40 & 5.75 & 7.99 & 41.85 & 58.15 \\
PSM50 & 50 & 50 & 5.36 & 9.98 & 32.66 & 67.34 \\
PSM40 & 40 & 60 & 3.83 & 11.98 & 24.23 & 75.77 \\
PSM30 & 30 & 70 & 2.87 & 13.98 & 17.032 & 82.96 \\
PSM20 & 20 & 80 & 1.97 & 15.98 & 10.97 & 89.03 \\
\hline
\end{tabular}

on the surface of polymeric materials were investigated by the JEOL JSM-6490LA scanning electron microscope and OPTIKA 600 optical microscope, respectively.

Antibacterial activity was performed by the disk diffusion method using gentamycin as a negative control and PMMA as a positive control. Bacteria were stored in a lag phase at $-4^{\circ} \mathrm{C}$ in the form of agar plate and activated before antibacterial assay. Bacteria were streaked on a freshly prepared Mueller-Hinton agar (MHA) plate and put into an oven already set at $37^{\circ} \mathrm{C}$ for 24 hours. Bacterial colony from new growth was mixed into saline, and optical density was set 0.5 by using the McFarland standard after centrifuging. Bacterial cultures $(1 \mathrm{ml})$ of $E$. coli and $S$. aureus were poured on agar. MHA plates were again placed in the oven at $37^{\circ} \mathrm{C}$ for 24 hours, and the zone of inhibitions was observed [33]. All experiments were performed at least three times, and the results are presented as the mean \pm standard deviation. Statistical significance was determined using the $t$-test $\left({ }^{*} p<0.05,{ }^{* *} p<0.01,{ }^{* * *} p<0.001\right.$, and $\left.{ }^{* * * *} p<0.0001\right)$ [34]. The biofilm formation test was performed for E. coli, ATCC 8739, and S. aureus ATCC 6538 in six-well plates, and as-prepared copolymers of size $0.5 \times 0.5 \mathrm{~cm}$ were put into each well for 24 hours. Retrieved samples were further treated with PBS, 4\% PFA, and different concentrations of ethanol. Drying was carried out in sterile petri plates to avoid contamination. After drying, samples were placed at $-4^{\circ} \mathrm{C}$ until subjected to SEM analysis [35]. Dictyosphaerium microalgae were employed for biofilm formation testing. Inocula of Dictyosphaerium were taken from freshly grown medium of optimum light and air. These cells were centrifuged and washed with distilled water. The optical density was set at 0.5 for the spectrophotometer [29]. The adhesion studies were carried out using Dictyosphaerium on prepared antifouling copolymers P(SPMA-Co-MMA), and comparative analysis was made by using each type of copolymer. The inoculum was prepared from the stock cultures by aptly reducing their concentration with BG11 to acquire $1.0 \times 1$ $0^{7} \mathrm{cell} / \mathrm{ml}$ suspension. Each sample of size $1 \times 1 \mathrm{~cm}^{2}$ was placed in a glass-sterilized petri dish, and algal suspension was poured on top of the copolymers. These petri plates were centrifuged at $40 \mathrm{rpm}$ under $85 \pm 10 \mu \mathrm{mol} \mathrm{m}^{-2} \mathrm{~S}^{-1}$ of illumination. After a period of 7 days, polymeric samples were recovered from the plates and thoroughly washed with distilled water. Fixation of algal cells was further proceeded by washing copolymers with $2.5 \%$ glutaraldehyde, $0.1 \mathrm{M}$ phosphate buffer, and different concentrations of ethanol, respectively.
Optical microscopy was used to check algal adhesion on copolymers P(SPMA-co-MMA) [29].

\section{Results and Discussion}

3.1. FTIR Analysis. Various prepared samples of PSPMA, PMMA, and P(SPMA-co-MMA) were analyzed by FTIR spectroscopy to study their functional groups in Figure 2. In the FTIR spectrum of PSPMA, the band at $2960 \mathrm{~cm}^{-1}$ was due to $\mathrm{C}-\mathrm{H}$ asymmetric stretching vibration [36] while absorption at $2897 \mathrm{~cm}^{-1}$ was assigned to $\mathrm{C}-\mathrm{H}$ symmetric stretching vibration [37]. $\mathrm{C}=\mathrm{O}$ stretching vibration was depicted at $1726 \mathrm{~cm}^{-1}$ [37], and the band at $1450 \mathrm{~cm}^{-1}$ was attributed to saturated ester [38]. This spectrum has shown $\mathrm{C}-\mathrm{H}$ asymmetric deformation of $\mathrm{CH}_{3}$ at $1485 \mathrm{~cm}^{-1}$ and $\mathrm{C}$ $-\mathrm{H}$ symmetric deformation of $\mathrm{CH}_{3}$ at $1475 \mathrm{~cm}^{-1}$ [30]. The signals at $1190 \mathrm{~cm}^{-1}$ and $1041 \mathrm{~cm}^{-1}$ were assigned to symmetric stretching vibration and asymmetric stretching vibration of the $\mathrm{SO}_{3}$ group [30]. In the FTIR spectrum of PMMA, the band at $1433 \mathrm{~cm}^{-1}$ was assigned to the asymmetric bending vibration of the $\mathrm{CH}_{3}$ group of PMMA [39]. The absorption value at $1381 \mathrm{~cm}^{-1}$ was due to $\mathrm{OCH}_{3}$ deformation of PMMA [39]. The characteristic signals observed at $1265 \mathrm{~cm}^{-1}$ and $1145 \mathrm{~cm}^{-1}$ correspond to $\mathrm{C}-\mathrm{O}-\mathrm{C}$ stretching and bending, respectively [39]. The FTIR band at $1193 \mathrm{~cm}^{-1}$ was due to $\mathrm{OCH}_{3}$ stretching vibration. Vibrations at $977 \mathrm{~cm}^{-1}$ and $716 \mathrm{~cm}^{-1}$ were assigned to the $\mathrm{CH}_{2}$ wagging and rocking modes of PMMA, respectively [40].

In the PSM50 spectrum, characteristic bands were observed at $749 \mathrm{~cm}^{-1}$ due to stretching of the $-\mathrm{CH}_{2}$ group of polymer [38]. The FTIR band was obtained at $1041 \mathrm{~cm}^{-1}$ due to asymmetric stretching vibration of $\mathrm{SO}_{3}$ [41]. The bands due to $-\mathrm{C}-\mathrm{O}$ stretching vibration of esters were read at $1354 \mathrm{~cm}^{-1}$ and $1145 \mathrm{~cm}^{-1}$ [19]. In the FTIR spectra of PSPMA, PMMA, and P(SPMA-co-MMA), no absorption was observed for $\mathrm{C}=\mathrm{C}$ bond in the $1610-1680 \mathrm{~cm}^{-1}$ range; this has confirmed that polymerization was taking place at the vinyl group due to which $\mathrm{C}=\mathrm{C}$ double bond signals disappeared [37].

3.2. ${ }^{1} \mathrm{H}-\mathrm{NMR}$ Spectroscopy. The ${ }^{1} \mathrm{H}-\mathrm{NMR}$ spectrum of P(SPMA-co-MMA) copolymer's PSM50 sample in Figure 3 has illustrated that the different chemical shift peaks in DMSO at $343 \mathrm{~K}$ corresponded to various proton environments in different chemical moieties present in copolymer [39]. Signals of MMA and SPMA are well observed in the spectrum. There are notable variations in the dynamic motion of protons that validate the structure of copolymer and as a result of association phenomena which depicted eloquent spectral changes [42]. In this spectrum, a standard prominent peak due to DMSO solvent was observed at $2.5 \mathrm{ppm}$ [43]. Another characteristic peak due to the $\mathrm{OCH}_{2}$ group of SPMA was observed slightly upward at $4.2 \mathrm{ppm}$ [42]. Furthermore, a signal was read at $2.72 \mathrm{ppm}$ due to $\mathrm{CH}_{2} \mathrm{SO}_{3} \mathrm{~K}$ resonance [42]. The inset showed resonance at 3.1-3.5 ppm which also has indicated the formation of copolymer [43]. The peaks at $1.1 \mathrm{ppm}$ and $1.8 \mathrm{ppm}$ have represented methyl groups along the chains that are surrounded by different environments [38]. 


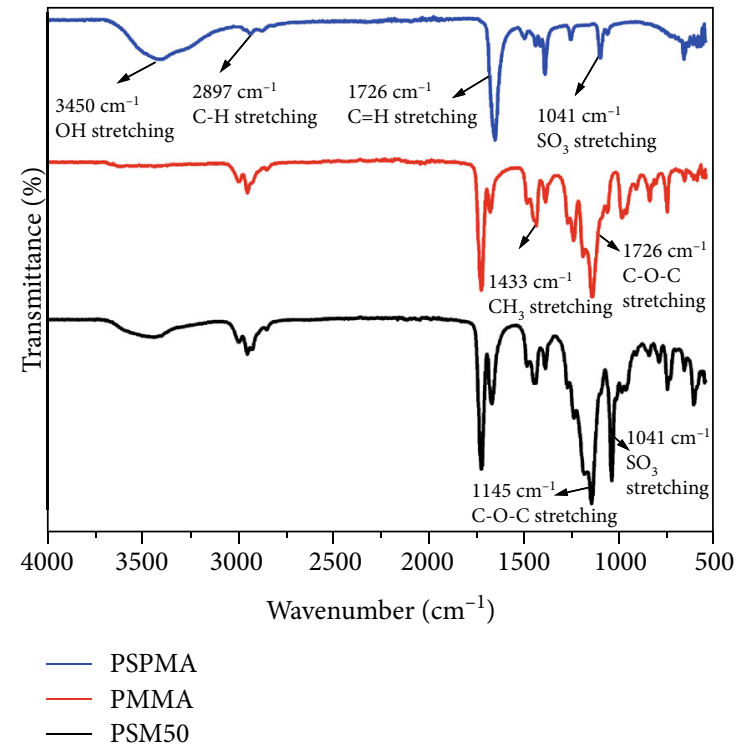

FIGURE 2: FTIR spectra of as-synthesized samples: poly-3sulfopropyl methacrylate (PSPMA), polymethylmethacrylate (PMMA), and PSM50 copolymer of P(SPMA-co-MMA).

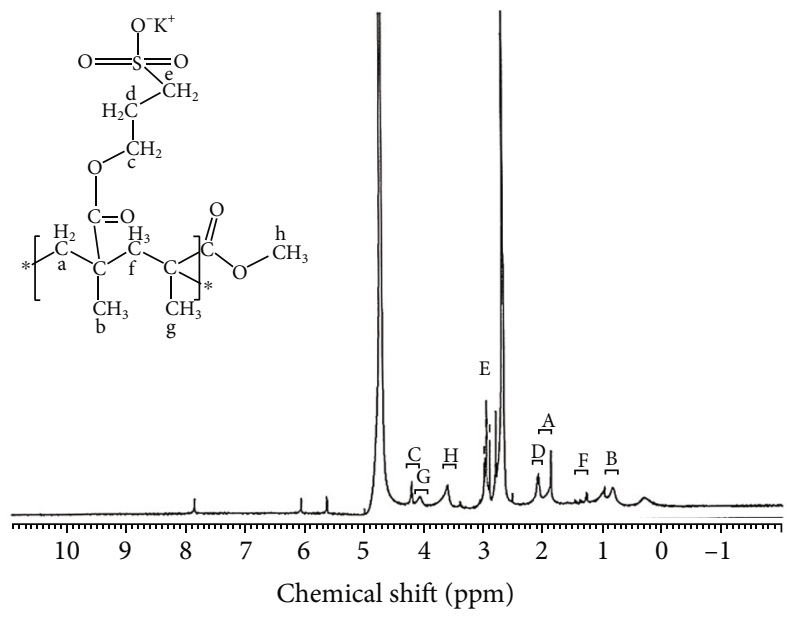

Figure 3: ${ }^{1} \mathrm{H}-\mathrm{NMR}$ of PSM50 copolymer of P(SPMA-co-MMA).

3.3. UV-Vis Spectroscopy. UV-Vis spectra in Figure 4 of $\mathrm{P}$ (SPMA-co-MMA) copolymers have shown absorbance in the range of 200-320 nm wavelength. It is evident from spectra that PSM20 and PSM30 have greater transmittance $\approx 88 \%$ and $\approx 85 \%$ as compared to PSM 40 and PSM50 that have $\approx 81 \%$ and $\approx 76 \%$, respectively. Copolymers PSM50 and PSM40 have shown intense absorbance below $300 \mathrm{~nm}$ as compared to PSM30 and PSM20. This absorption edge was generated due to the electronic excitation within the sulfonyl group $(\mathrm{O}=\mathrm{S}=\mathrm{O})$ and carbonyl group $(\mathrm{C}=\mathrm{O})$ chromophores present in copolymers [38]. The most intense absorption band detected in the spectra from 200 to $250 \mathrm{~nm}$ is due to $\pi$ $-\pi^{*}$ transition in the $\mathrm{O}=\mathrm{S}=\mathrm{O}$ and $\mathrm{C}=\mathrm{O}$ systems [44].

Figure 4 has also depicted the transmittance as a function of incident light wavelength while transmittance decreased and absorbance increased with increasing the concentration

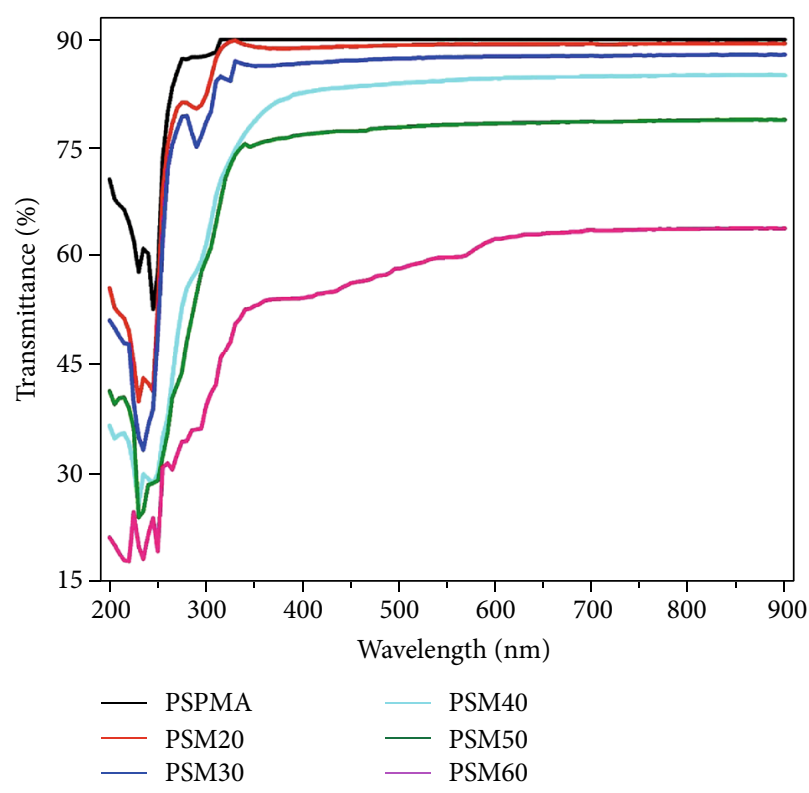

FIGURE 4: UV-Visible spectra of the synthesized copolymers of poly3-sulfopropyl methacrylate and methyl methacrylate, P(SPMA-coMMA).

of SPMA monomer in copolymers PSM20 to PSM60. However, transmittance of PSM60 was significantly decreased upon increasing SPMA concentration which resulted in loss of transparency. This is due to the presence of free electrons in SPMA that absorb the electromagnetic energy of the incident light and excited to higher energy levels to occupy energy bands that caused less light penetration through it [45]. As concluded from Figure 4, transparency of PSM60 was quite low so it was insignificant for further characterization and application. On the other hand, the MMA monomer has high transmittance because MMA has no free electrons that move towards the conduction band on photon absorption [45].

Transparency of these copolymers was affected after biofilm formation as shown in Figure 5. PSM50 has greater concentration of SPMA monomer and is expected to possess higher antifouling property due to hydrophilic negatively charged sulfonated groups. Copolymers with more SPMA monomer resulted in minimal adhesion of microorganisms and low biofilm that lead to small decrease in percent transmittance. In PSM50, concentration of SPMA monomer was $50 \%$, and $2 \%$ decrease in transmittance was observed after biofilm formation while in PSM20 concentration of SPMA monomer was $20 \%$ resulting in more adhesion of fouling organisms; thus, $6 \%$ decrease in transmittance was observed after biofilm formation. Copolymers PSM40 and PSM30 with $40 \%$ and $30 \%$ of SPMA monomer contents by weight exhibited transmittance between PSM50 and PSM20 with 3 $\pm 2 \%$ transmittance decrease after biofilm formation.

3.4. Contact Angle and Surface Energy Measurement. Contact angles of the synthesized copolymers P(SPMA-co-MMA) were observed to be highly dependent on the molar ratio of SPMA monomer in Figure 6. Copolymers PSM50, PSM40, 


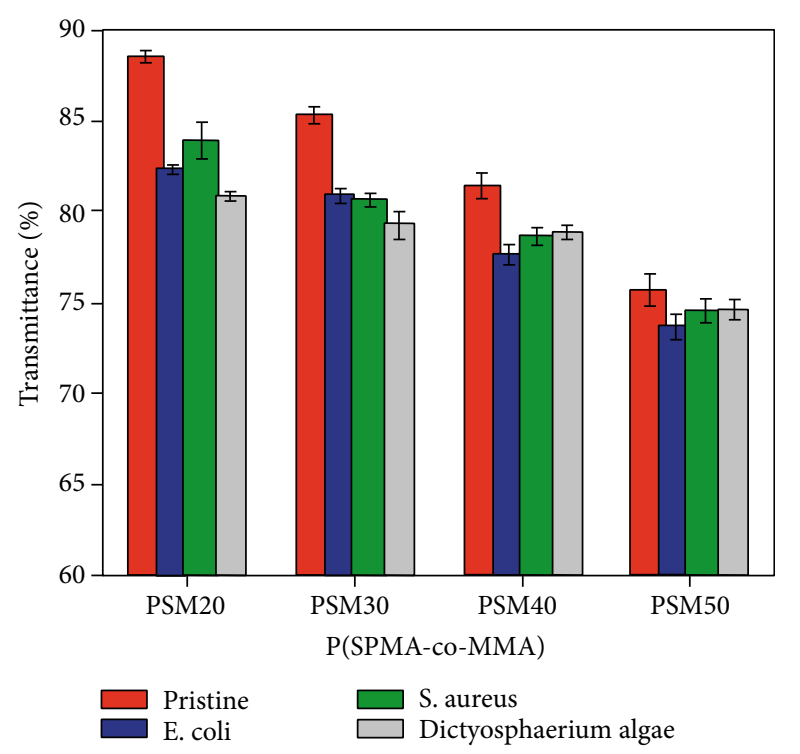

FIGURE 5: \%Transmittance comparison of copolymers of P(SPMAco-MMA); before (pristine) and after biofilm formation against $E$. coli, S. aureus, and Dictyosphaerium algae.

PSM30, and PSM20 have demonstrated contact angles $17^{\circ}$, $29^{\circ}, 56^{\circ}$, and $63^{\circ}$, respectively. The water contact angle is notably influenced by the interactions of polar liquid, e.g., water with hydrophilic functional groups of P(SPMA-coMMA) copolymer like the $\mathrm{SO}_{3}$ group [46]. At the waterpolymer interface, there are polar water molecule interactions and orientation with anionic functional groups of polymer structural chain [46]. Water molecules on a polymer chain can be directed away from the solid-gas interface after changing their orientation [37]. The apparent surface free energy was also estimated based on the equilibrium water contact angle approach [47]. Surface energy is increased with the decrease in the equilibrium water contact angles as clearly reflected in Figure 6 [46]. The calculated surface free energy values are dependent upon the physicochemical properties of the water [48]. Chibowski correlation, Young equation, and the equilibrium contact angle were applied for the computation of apparent surface free energy [46, 49]:

$$
\gamma_{\mathrm{s}}=\frac{\gamma_{1}}{2}\left(1+\cos \theta_{\mathrm{Eq}}\right)
$$

where $\gamma_{\mathrm{s}}$ is the apparent surface free energy, $\gamma_{1}$ is the liquid surface tension, and $\theta_{\mathrm{Eq}}$ is the equilibrium contact angle.

3.5. Antibacterial Activity. The antibacterial activity of copolymers P(SPMA-co-MMA) with various concentrations of SPMA was performed against Gram-positive bacteria $S$. aureus and Gram-negative bacteria E. coli by the disk diffusion method while measurements were recorded in terms of inhibition zones. Figures 7(a) and 7(b) represent the evaluation of antifouling activity of the copolymers compared with a drug (gentamycin) as a positive control and PMMA as a negative control, respectively. It was observed that synthesized copolymers have significant antibacterial activity

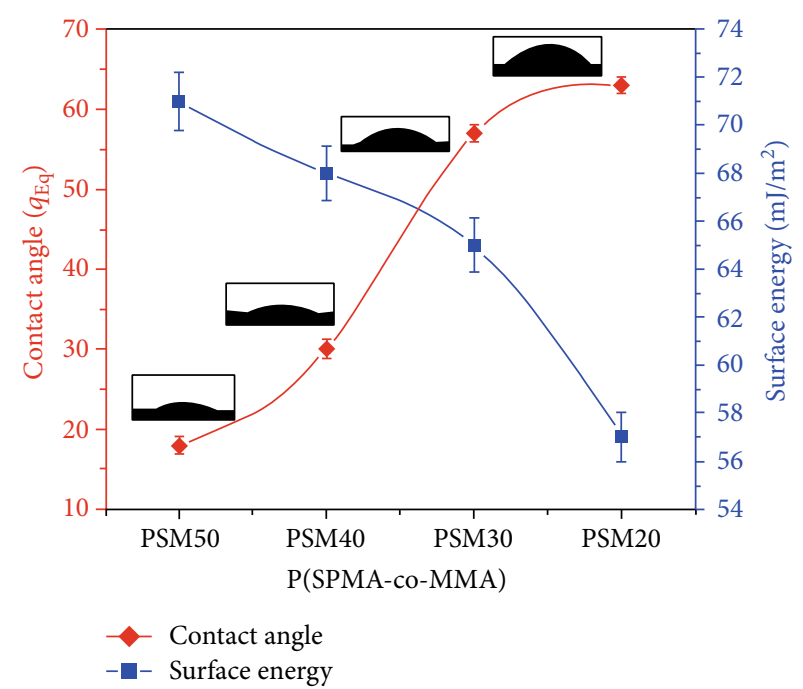

FIgURE 6: Contact angles and surface energy of the prepared copolymers of P(SPMA-co-MMA).

against E. coli and S. aureus. The statistical analysis of copolymers was performed using the paired two-tailed $t$-test technique by establishing the mean and standard deviation of an individual copolymer. Error bars show the standard deviation, and asterisks $(*)$ represent significant $p$ values.

It was observed that antibacterial activity was enhanced by increasing concentration of anionic SPMA hydrophilic monomer in the synthesized copolymers P(SPMA-coMMA) [50]. Bacterial settlement and adhesion are primarily dependent upon surface roughness, hydrophobicity, hydrophilicity, and electrostatic charges present on the material surfaces [25, 51]. In these synthesized copolymers, the anionic sulfonated group produced electrostatic repulsive forces on the material surface $[37,42]$. These electrostatic repulsive forces played a vital role in forming significant inhibition zones with the increase of the SPMA monomer contents [43]. The bacterial cell wall is made up of macromolecules comprising carboxylate, phosphate, and amino functional groups that induced electrostatic charge to the cell periphery [52]. Both bacteria $S$. aureus and E. coli have a negative charge on the outer surface due to phospholipids in the structure and repelled by the copolymers containing anionic $\mathrm{SO}_{3}$ groups in SPMA monomer due to repulsive electrostatic interactions [53]. These results suggested that higher concentrations of SPMA monomer in the copolymer compositions may have produced more repulsion between polymer and bacteria $[35,54]$. This increase in SPMA monomer concentration in copolymers resulted in enhanced water hydrogen bonding and lower fouling [21]. These anionic copolymers are capable of effectively interacting with water molecules that resulted in lower settlement of bacteria to higher extent [35].

3.6. SEM Analysis of Bacterial Biofilm. Biofilm formation on the surface of prepared copolymers was also studied by SEM technique in Figures 8 and 9. Biofilm development, composition, distribution, and substratum relationships are well investigated by SEM technique in literature [55-57]. 


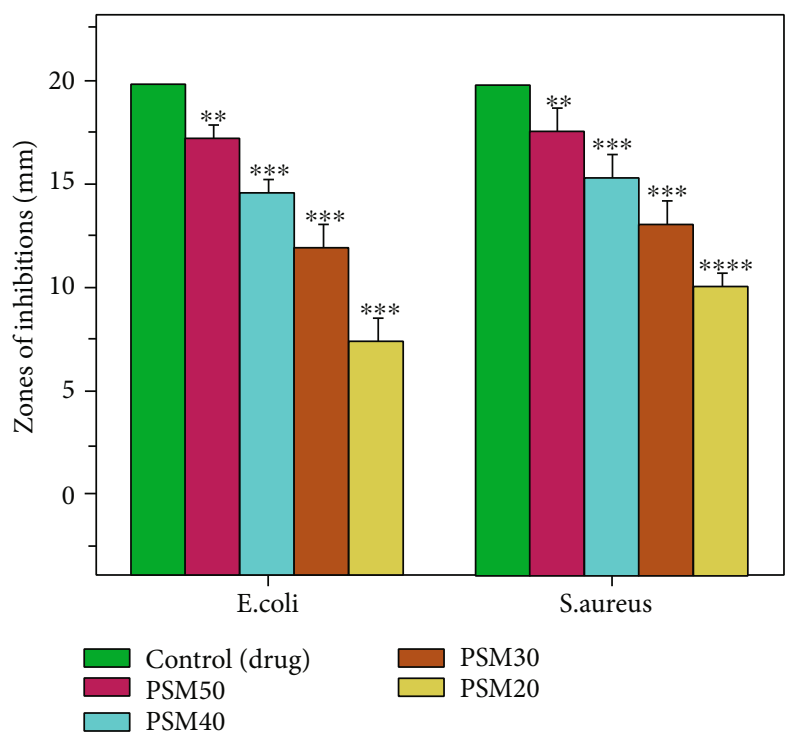

(a)

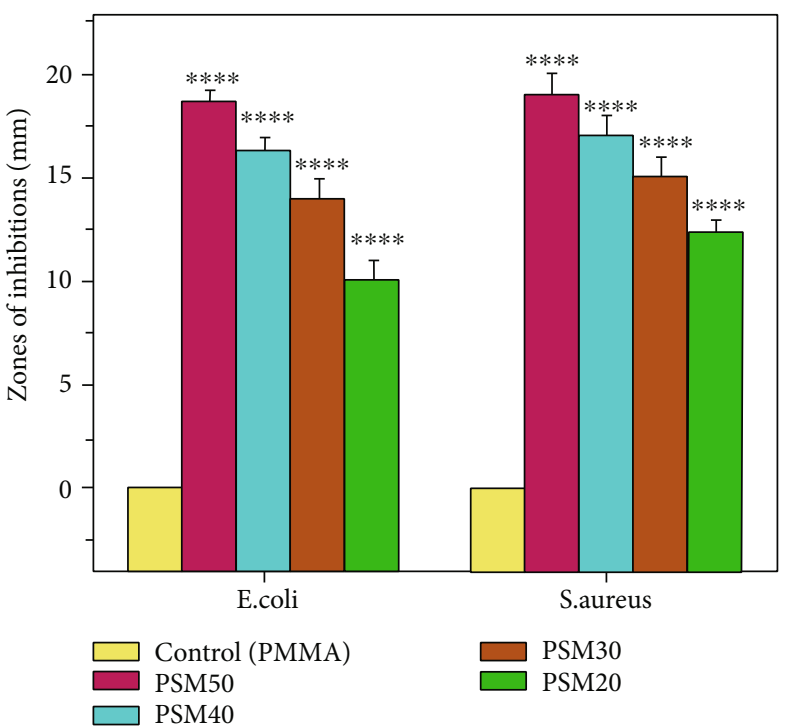

(b)

FIgure 7: Zones of inhibition of PSM50, PSM40, PSM30, and PSM20 for E. coli and S. aureus: (a) with drug (+ive control) and (b) with PMMA (-ive control).

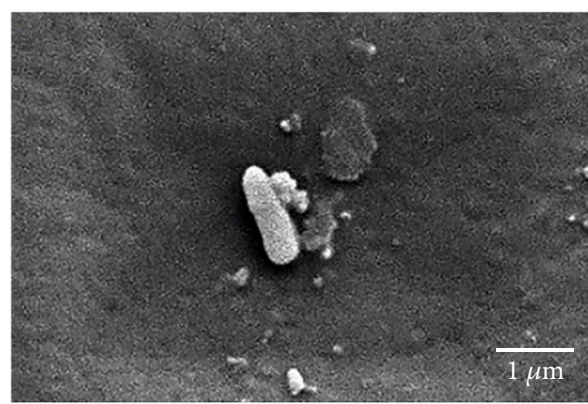

(a)

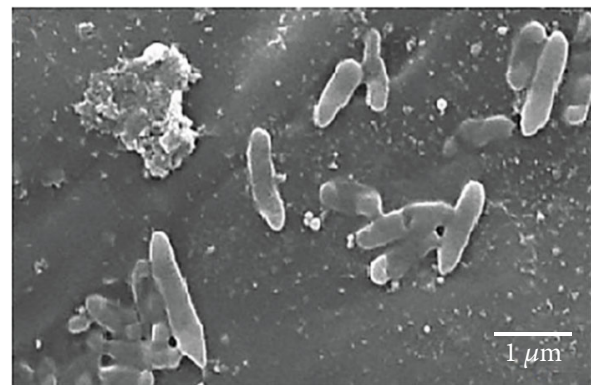

(c)

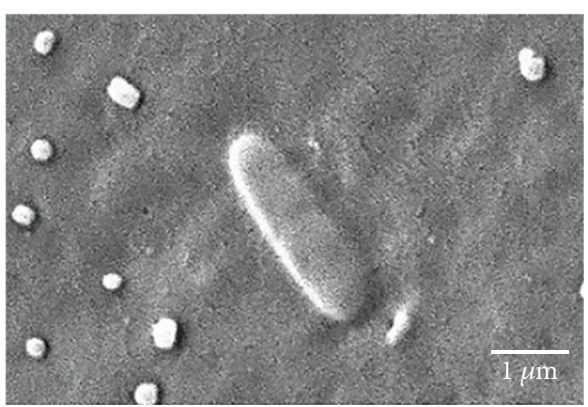

(b)

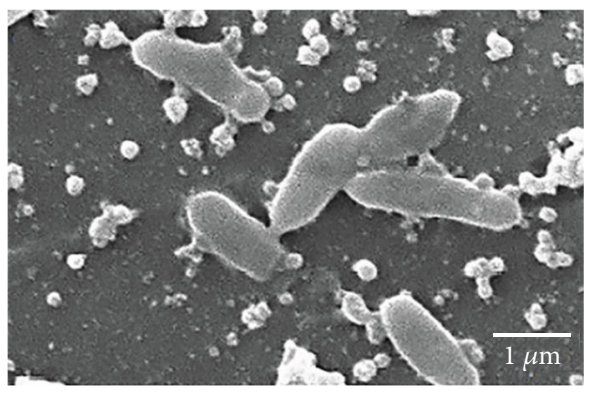

(d)

FIgURE 8: SEM images of E. coli biofilm adhesion on (a) PSM50, (b) PSM40, (c) PSM30, and (d) PSM20.

As evident, the synthesized copolymers exhibited excellent antibacterial activity against E. coli and S. aureus. Adhesion of these bacteria was reduced on synthesized copolymer due to electrostatic repulsion as a result of identical negative charges on materials and bacterial surface [58]. In these copolymers, sulfonated groups of SPMA monomer have been increased from PSM20 to PSM50 by $20-50 \mathrm{wt} \%$ that enhanced hydration and lower $\mathrm{pH}$ which apply stress on the outer membrane of these tested bacteria by exerting pres- sure on the bacterial cell wall [59]. SEM images have also shown low adhesion of E. coli and $S$. aureus on the surface due to the hydrophilic and anionic nature of SPMA monomer $[49,51]$. The bacteria motility is expected to diminish on negatively charged polymers and resulted in protein denaturation, enzyme denaturation, and microbial death by rupturing the cell wall of Gram-negative bacteria E. coli and Gram-positive bacteria S. aureus $[35,53,60]$. In Figures 8 and 9, adhesion of E. coli and S. aureus on the surface of 


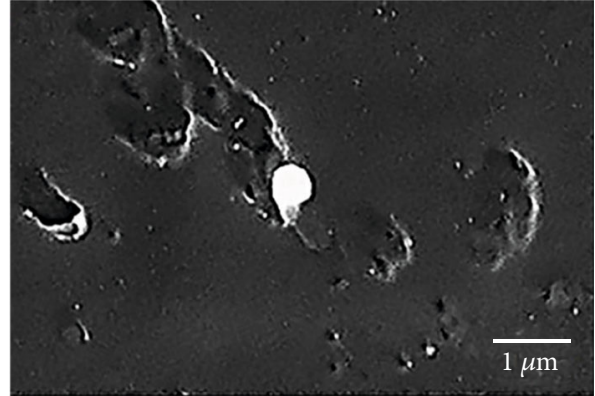

(a)

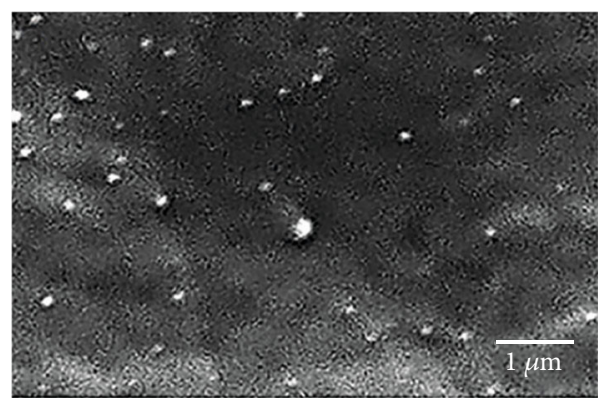

(c)

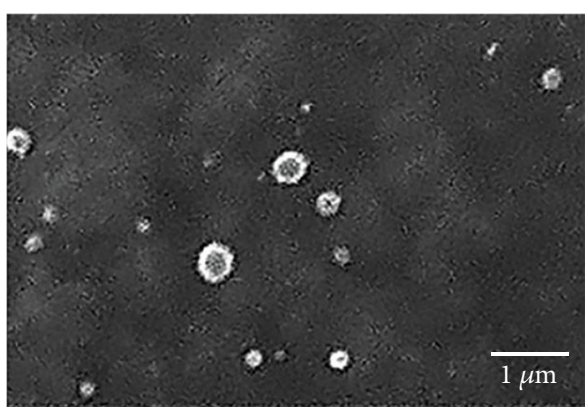

(b)

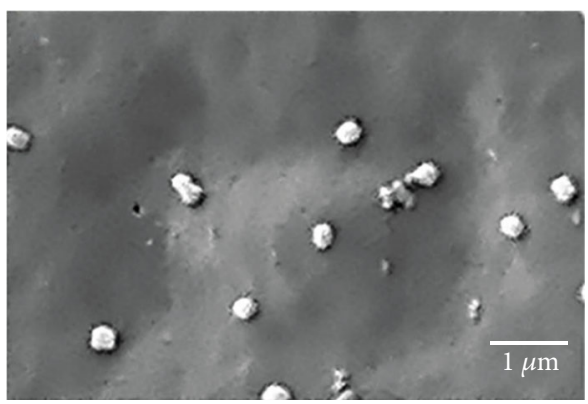

(d)

FIGURE 9: SEM images of S. aureus biofilm adhesion on (a) PSM50, (b) PSM40, (c) PSM30, and (d) PSM20.

PSM50 and PSM40 was low due to greater content of SPMA monomer as compared to PSM30 and PSM20 with less content of anionic SPMA monomer. This biofilm formation and adhesion were controlled by electrostatic repulsion between bacteria and surface of material $[5,61]$. On the other hand, rupturing of the bacterial cell wall was also observed in SEM images of E. coli in Figures 8(a) and 8(c) and S. aureus in Figures 9(a) and 9(b) due to charged polymers and protein denaturation.

3.7. Optical Microscopy of Algal Biofilm. Optical microscopic images of algal biofilm on prepared copolymer surfaces are presented in Figure 10. Results have shown lower adhesion of Dictyosphaerium algae on PSM50 and PSM40 due to higher concentration of SPMA monomer in the synthesized copolymers. Adhesion of algae depends on multiple factors like material chemical nature, charge on algae, and surface free energy [21]. These parameters measure the ability of a surface to interlink with other materials by interactions that highly depend on interfacial surface energies [21]. The hydrophilic nature of SPMA monomer leads to the hydration layer on the surface of material that resulted in low algal biofilm formation on the surface [62]. Higher concentration of SPMA monomer also caused high surface energy thus showing minimum adhesion of algal cells [63].

The adhesions of Dictyosphaerium algae on P(SPMA-coMMA) copolymers were decreased due to electrostatic repulsion that originated as a result of similar negative charges on the cell membrane of Dictyosphaerium algae and copolymer [64]. Greater repulsion upon algal species Dictyosphaerium and minimum algal adhesion on surface were demonstrated in PSM50 and PSM40 due to higher negatively charged con- tent of SPMA monomer as compared to PSM30 and PSM20 [64].

\section{Conclusion}

P(SPMA-co-MMA) copolymers were successfully synthesized by free radical polymerization with varying wt $\%$ of methyl methacrylate (MMA) and 3-sulfopropyl methacrylate (SPMA) monomers. These copolymer samples PSM50, PSM40, PSM30, and PSM20 were transparent while percent transmittance was increased by increasing MMA contents from 50\% (PSM50) to 80\% (PSM20). However, copolymer sample PSM60 has lost transparency owing to low contents of MMA, i.e., $40 \%$. Water contact angle values of copolymers were varied from $20^{\circ}$ to $65^{\circ}$ by varying contents of hydrophilic SPMA monomer and hydrophobic MMA monomer. Surface energy of the synthesized copolymers ranged from $57 \mathrm{~mJ} / \mathrm{m}^{2}$ to $70 \mathrm{~mJ} / \mathrm{m}^{2}$. These copolymers have exhibited good antifouling activity against bacteria $E$. coli and $S$. aureus and against microalgae Dictyosphaerium. The transparent antifouling polymers have shown low bacterial and algal biofilm formation with increasing content of SPMA monomer due to electrostatic repulsion between bacteria and polymers. SEM images showed rupturing of the bacterial cell wall due to hydration and decrease in $\mathrm{pH}$ which enhanced pressure on the outer membrane of bacteria. After biofilm formation, a slight decrease in transparency was observed around 2-8\% of copolymer samples due to the difference in adhesion capacity of microorganisms on different hydrophilic materials. Algal biofilm of Dictyosphaerium sp. has exhibited a low adhesion level owing to electrostatic repulsion between microalgae and anionic copolymers. PSM50 had more 


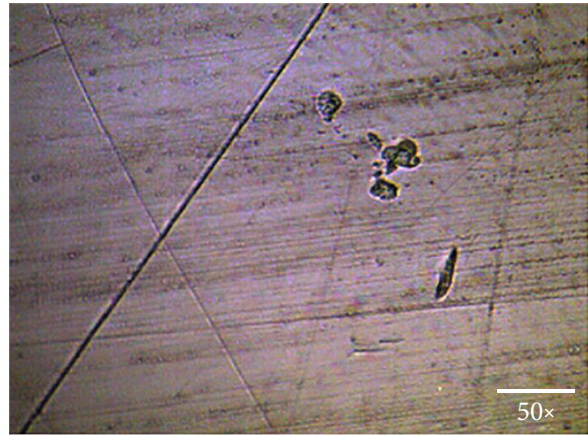

(a)

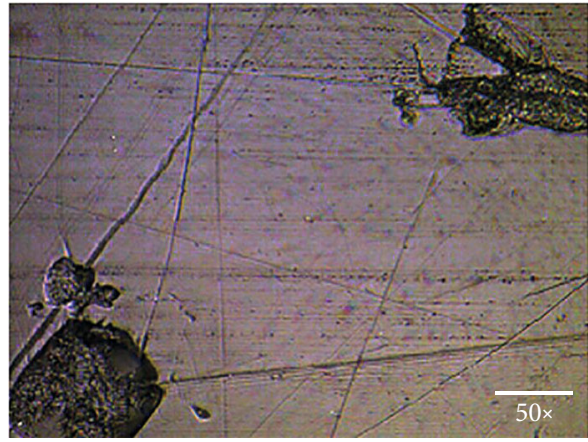

(c)

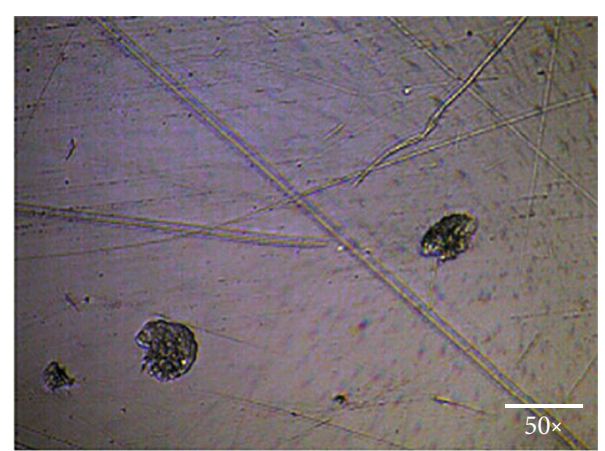

(b)

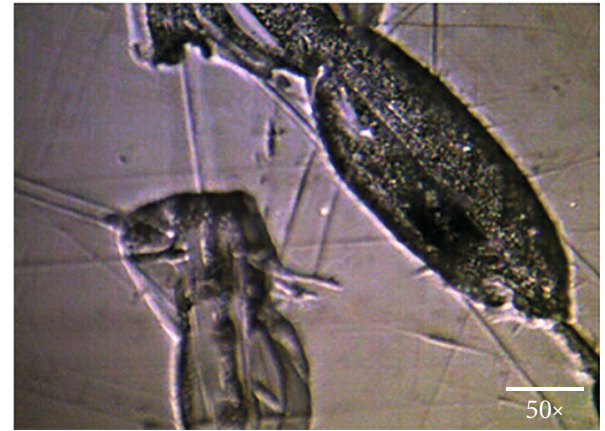

(d)

FIGURE 10: Optical microscopy of algal biofilm of Dictyosphaerium for the various copolymers of P(SPMA-co-MMA): (a) PSM50, (b) PSM40, (c) PSM30, and (d) PSM20.

hydrophilicity and greater negatively charged sulfonated group of SPMA monomer that lead to more repulsion and low settlement of algae on the polymer surfaces. These tailor-designed P(SPMA-co-MMA) copolymers have exhibited significantly higher transparency and inhibit biofilm formation on the surface that make them promising candidate materials for various applications including optronics in aquatic media, healthcare, and biotechnology.

\section{Data Availability}

The data used to support the findings of this study is included within the article.

\section{Conflicts of Interest}

The authors declare no conflict of interest.

\section{Acknowledgments}

The authors are grateful to the National University of Sciences and Technology Research Directorate for financial support. Dr. Nasir M. Ahmad acknowledges the support of HEC, NRPU, through Project No. 3526.

\section{References}

[1] C. Wu, Y. Zhou, H. Wang, J. Hu, and X. Wang, "Formation of antifouling functional coating from deposition of a zwitterionic-co-nonionic polymer via "grafting to" approach,"
Journal of Saudi Chemical Society, vol. 23, no. 8, pp. 10801089, 2019.

[2] A. Alamri, M. H. el-Newehy, and S. S. al-Deyab, "Biocidal polymers : synthesis and antimicrobial properties of benzaldehyde derivatives immobilized onto amine-terminated polyacrylonitrile," Chemistry Central Journal, vol. 6, no. 1, p. 1, 2012.

[3] L. Timofeeva and N. Kleshcheva, "Antimicrobial polymers: mechanism of action, factors of activity, and applications," Applied Microbiology and Biotechnology, vol. 89, no. 3, pp. 475-492, 2011.

[4] J. Baggerman, M. M. J. Smulders, and H. Zuilhof, "Romantic surfaces: a systematic overview of stable, biospecific, and antifouling zwitterionic surfaces," Langmuir, vol. 35, no. 5, pp. 1072-1084, 2019.

[5] V. B. Damodaran and N. S. Murthy, "Bio-inspired strategies for designing antifouling biomaterials," Biomaterials Research, vol. 20, no. 1, pp. 1-11, 2016.

[6] M. A. Hood, M. Mari, and R. Muñoz-Espí, "Synthetic strategies in the preparation of polymer/inorganic hybrid nanoparticles," Materials, vol. 7, no. 5, pp. 4057-4087, 2014.

[7] K. Müller, E. Bugnicourt, M. Latorre et al., "Review on the processing and properties of polymer nanocomposites and nanocoatings and their applications in the packaging, automotive and solar energy fields," Automotive and Solar Energy Fields, vol. 7, no. 4, p. 74, 2017.

[8] R. Nugraha, J. A. Finlay, S. Hill et al., "Antifouling properties of oligo (lactose)-based self-assembled monolayers," Biofouling, vol. 31, no. 1, pp. 123-134, 2014.

[9] M. Salta, J. A. Wharton, P. Stoodley et al., "Designing biomimetic antifouling surfaces," Philosophical Transactions of the 
Royal Society A - Mathematical Physical and Engineering Sciences, vol. 368, no. 1929, pp. 4729-4754, 2010.

[10] E. F. Palermo, I. Sovadinova, and K. Kuroda, "Structural determinants of antimicrobial activity and biocompatibility in membrane-disrupting methacrylamide random copolymers," Biomacromolecules, vol. 10, no. 11, pp. 3098-3107, 2009.

[11] B. van Bochove and D. W. Grijpma, "Photo-crosslinked synthetic biodegradable polymer networks for biomedical applications," Journal of Biomaterials Science. Polymer Edition, vol. 30, no. 2, pp. 77-106, 2019.

[12] H. Palza, "Antimicrobial polymers with metal nanoparticles," International Journal of Molecular Sciences, vol. 16, no. 1, pp. 2099-2116, 2015.

[13] L. T. Curtis, "Prevention of hospital-acquired infections: review of non-pharmacological interventions," The Journal of Hospital Infection, vol. 69, no. 3, pp. 204-219, 2008.

[14] E. R. Kenawy, S. D. Worley, and R. Broughton, "The chemistry and applications of antimicrobial polymers: a state-of-the-art review," Biomacromolecules, vol. 8, no. 5, pp. 1359-1384, 2007.

[15] A. Debuigne, T. Radhakrishnan, and M. K. Georges, "Stable free radical polymerization of acrylates promoted by $\alpha$-hydroxycarbonyl compounds," Macromolecules, vol. 39, no. 16, pp. 5359-5363, 2006.

[16] P. Acrylates, D. Avci, K. Avi, and E. Tu, "Modeling the free radical polymerization of acrylates," International Journal of Quantum Chemistry, vol. 103, no. 2, pp. 176-189, 2005.

[17] S. Purser, P. R. Moore, S. Swallow, and V. Gouverneur, "Fluorine in medicinal chemistry," Chemical Society Reviews, vol. 37, no. 2, pp. 320-330, 2008.

[18] K. Yamada, T. Nakano, and Y. Okamoto, "Stereospecific free radical polymerization of vinyl esters using fluoroalcohols as solvents," Macromolecules, vol. 31, no. 22, pp. 7598-7605, 1998.

[19] H. J. Patel, M. G. Patel, A. K. Patel, K. H. Patel, and R. M. Patel, "Synthesis, characterization and antimicrobial activity of important heterocyclic acrylic copolymers," eXPRESS Polymer Letters, vol. 2, no. 10, pp. 727-734, 2008.

[20] M. B. Dolia, U. S. Patel, A. Ray, and R. M. Patel, "Synthesis, characterization and antimicrobial activity of novel acrylic copolymers," Polymer Journal, vol. 38, no. 2, pp. 159-170, 2006.

[21] M. A. Bag and L. M. Valenzuela, "Impact of the hydration states of polymers on their hemocompatibility for medical applications: a review," International Journal of Molecular Sciences, vol. 18, no. 8, p. 1422, 2017.

[22] J. Wu, W. Lin, Z. Wang, S. Chen, and Y. Chang, "Investigation of the hydration of nonfouling material poly (sulfobetaine methacrylate) by low-field nuclear magnetic resonance," Langmuir, vol. 28, no. 19, pp. 7436-7441, 2012.

[23] R. O. Darouiche, "Antimicrobial approaches for preventing infections associated with surgical implants," Clinical Infectious Diseases, vol. 36, no. 10, pp. 1284-1289, 2003.

[24] A. R. El-Nahas, M. Lachine, E. Elsawy, A. Mosbah, and H. ElKappany, "A randomized controlled trial comparing antimicrobial (silver sulfadiazine)-coated ureteral stents with noncoated stents," Scandinavian Journal of Urology, vol. 52, no. 1, pp. 76-80, 2018.

[25] Y. J. Oh, E. S. Khan, A. CampoDel, P. Hinterdorfer, and B. Li, "Nanoscale characteristics and antimicrobial properties of (SIATRP)-seeded polymer brush surfaces," ACS Applied Materials \& Interfaces, vol. 11, no. 32, pp. 29312-29319, 2019.
[26] T. Mai, E. Rakhmatullina, K. Bleek et al., "Poly (ethylene oxide)- b -poly(3-sulfopropyl methacrylate) block copolymers for calcium phosphate mineralization and biofilm inhibition," Biomacromolecules, vol. 15, no. 11, pp. 3901-3914, 2014.

[27] V. Cepas, Y. López, Y. Gabasa et al., "Inhibition of bacterial and fungal biofilm formation by 675 extracts from microalgae and cyanobacteria," Antibiotics, vol. 8, no. 2, p. 77, 2019.

[28] A. Muñoz-Bonilla and M. Fernández-García, "Polymeric materials with antimicrobial activity," Progress in Polymer Science, vol. 37, no. 2, pp. 281-339, 2012.

[29] F. Pillet, E. Dague, J. Pe, and I. Ru, "Changes in nanomechanical properties and adhesion dynamics of algal cells during their growth," Bioelectrochemistry, vol. 127, pp. 154-162, 2019.

[30] T. Mai, K. Wolski, A. Puciul-Malinowska et al., "Anionic polymer brushes for biomimetic calcium phosphate mineralization - a surface with application potential in biomaterials," Polymers, vol. 10, no. 10, p. 1165, 2018.

[31] T. Kaino, "Optical Absorption of Polymers," in Encyclopedia of Polymeric Nanomaterials, S. Kobayashi and K. Müllen, Eds., Springer, Berlin, Heidelberg, 2014.

[32] D. P. Subedi, "Contact angle measurement for the surface characterization of solids," Himalayan Physics, vol. 2, pp. 14, 2011.

[33] K. Hoelzer, K. J. Cummings, L. D. Warnick et al., “Agar disk diffusion and automated microbroth dilution produce similar antimicrobial susceptibility testing results for Salmonella serotypes Newport, Typhimurium, and 4,5,12:i-, but differ in economic cost," Foodborne Pathogens and Disease, vol. 8, no. 12, pp. 1281-1288, 2011.

[34] Y. Wang, Y. Lu, J. Zhang et al., "A synergistic antibacterial effect between terbium ions and reduced graphene oxide in a poly(vinyl alcohol)-alginate hydrogel for treating infected chronic wounds," Journal of Materials Chemistry B, vol. 7, no. 4, pp. 538-547, 2019.

[35] B. Ran, C. Jing, C. Yang, X. Li, and Y. Li, "Synthesis of efficient bacterial adhesion-resistant coatings by one-step polydopamine-assisted deposition of branched polyethylenimine-g-poly (sulfobetaine methacrylate) copolymers," Applied Surface Science, vol. 450, pp. 77-84, 2018.

[36] J. Gu, S. Yuan, W. Shu, W. Jiang, S. Tang, B. Liang et al., "PVBC microspheres tethered with poly(3-sulfopropyl methacrylate) brushes for effective removal of $\mathrm{Pb}$ (II) ions from aqueous solution," Colloids Surfaces A Physicochem Eng Asp, vol. 498, pp. 218-230, 2016.

[37] R. Patel, W. S. Chi, S. H. Ahn, C. H. Park, H. K. Lee, and J. H. Kim, "Synthesis of poly (vinyl chloride)-g-poly(3-sulfopropyl methacrylate) graft copolymers and their use in pressure retarded osmosis (PRO) membranes," Chemical Engineering Journal, vol. 247, pp. 1-8, 2014.

[38] M. Degirmenci, "Synthesis and characterization of novel welldefined end-functional macrophotoinitiator of poly(MMA) by ATRP," Journal of Macromolecular Science, Part A, vol. 42, no. 1, pp. 21-30, 2005.

[39] Shen, "Preparation and characterization of PMMA and its derivative via RAFT technique in the presence of disulfide as a source of chain transfer agent," Journal of Membrane and Separation Technology, pp. 117-128, 2012.

[40] C. Park, E. Y. Jung, H. J. Jang, G. T. Bae, B. Shin, and H. S. Tae, "Synthesis and properties of plasma-polymerized methyl methacrylate via the atmospheric pressure plasma polymerization technique," Polymers, vol. 11, no. 3, p. 396, 2019. 
[41] T. Turhan, Y. G. Avcıbası, and N. Sahiner, "Versatile p(3-sulfopropyl methacrylate) hydrogel reactor for the preparation of $\mathrm{Co}, \mathrm{Ni}$ nanoparticles and their use in hydrogen production," Journal of Industrial and Engineering Chemistry, vol. 19, no. 4, pp. 1218-1225, 2013.

[42] G. Masci, D. Bontempo, N. Tiso et al., "Atom transfer radical polymerization of potassium 3-sulfopropyl methacrylate: direct synthesis of amphiphilic block copolymers with methyl methacrylate," Macromolecules, vol. 37, no. 12, pp. 4464-4473, 2004.

[43] Y. Xu, A. Walther, and A. H. E. Müller, "Direct synthesis of poly(potassium 3-sulfopropyl methacrylate) cylindrical polymer brushes via ATRP using a supramolecular complex with crown ether," Macromolecular Rapid Communications, vol. 31, no. 16, pp. 1462-1466, 2010.

[44] N. Boens, L. Wang, V. Leen et al., "8-HaloBODIPYs and Their 8-(C, N, O, S) substituted analogues: Solvent dependent UVVis spectroscopy, variable temperature NMR, crystal structure determination, and quantum chemical calculations," The Journal of Physical Chemistry A, vol. 118, pp. 1576-1594, 2014.

[45] H. N. Najeeb, A. A. Balakit, G. A. Wahab, and A. K. Kodeary, "Study of the optical properties of poly (methyl methacrylate) (PMMA) doped with a new diarylethen compound," Academic Research International, vol. 5, pp. 48-56, 2014.

[46] K. Terpiłowski, "Apparent surface free energy of polymer/paper composite material treated by air plasma," International Journal of Polymer Science, vol. 2017, 8 pages, 2017.

[47] C. Rulison, "Measure surface energy: a tutorial designed to provide basic understanding of the concept of solid surface energy," Krus USA, 1999.

[48] T. S. Parreidt and M. Schmid, "Validation of a novel technique and evaluation of the surface free energy of food," Foods, vol. 6 , no. 4 , p. 31, 2017.

[49] J. A. Callow, M. E. Callow, L. K. Ista, G. Lopez, and M. K. Chaudhury, "The influence of surface energy on the wetting behaviour of the spore adhesive of the marine alga Ulva linza (synonym Enteromorpha linza)," Journal of The Royal Society Interface, vol. 2, no. 4, pp. 319-325, 2005.

[50] M. Ramstedt, N. Cheng, O. Azzaroni, D. Mossialos, H. J. Mathieu, and W. T. S. Huck, "Synthesis and characterization of poly (3-sulfopropylmethacrylate) brushes for potential antibacterial applications," Langmuir, vol. 23, no. 6, pp. 33143321, 2007.

[51] J. A. Finlay, M. E. Callow, L. K. Ista, G. P. Lopez, and J. A. Callow, "The influence of surface wettability on the adhesion strength of settled spores of the green alga Enteromorpha and the diatom Amphora," Integrative and Comparative Biology, vol. 42, no. 6, pp. 1116-1122, 2002.

[52] L. A. B. Rawlinson, S. M. Ryan, G. Mantovani, J. A. Syrett, D. M. Haddleton, and D. J. Brayden, "Antibacterial effects of poly (2-(dimethylamino ethyl)methacrylate) against selected gram-positive and gram-negative bacteria," Biomacromolecules, vol. 11, no. 2, pp. 443-453, 2010.

[53] J. S. Dickson and M. Koohmaraie, "Cell surface charge characteristics and their relationship to bacterial attachment to meat surfaces," Applied and Environmental Microbiology, vol. 55, no. 4, pp. 832-836, 1989.

[54] O. Rzhepishevska, S. Hakobyan, R. Ruhal, J. Gautrot, D. Barbero, and M. Ramstedt, "The surface charge of anti-bacterial coatings alters motility and biofilm architecture," Biomater Sci, vol. 1, pp. 589-602, 2013.
[55] M. E. Callow and R. L. Fletcher, "The influence of low surface energy materials on bioadhesion - a review," International Biodeterioration and Biodegradation, vol. 34, no. 3-4, pp. 333348, 1994.

[56] Y. Cheng, G. Feng, and C. I. Moraru, "Micro- and nanotopography sensitive bacterial attachment mechanisms: a review," Frontiers in Microbiology, vol. 10, 2019.

[57] G. A. James, L. Boegli, J. Hancock, L. Bowersock, A. Parker, and B. M. Kinney, "Bacterial adhesion and biofilm formation on textured breast implant shell materials," Aesthetic Plastic Surgery, vol. 43, no. 2, pp. 490-497, 2019.

[58] B. T. Benkhaled, S. Hadiouch, H. Olleik et al., "Elaboration of antimicrobial polymeric materials by dispersion of welldefined amphiphilic methacrylic SG1-based copolymers," Polymer Chemistry, vol. 9, no. 22, pp. 3127-3141, 2018.

[59] B. K. D. Ngo and M. A. Grunlan, "Protein resistant polymeric biomaterials," ACS Macro Letters, vol. 6, no. 9, pp. 992-1000, 2017.

[60] A. Terada, K. Okuyama, M. Nishikawa, S. Tsuneda, and M. Hosomi, "The effect of surface charge property on Escherichia coli initial adhesion and subsequent biofilm formation," Biotechnology and Bioengineering, vol. 109, no. 7, pp. 17451754, 2012.

[61] S. Krishnan, J. Weinman, and C. K. Ober, "Advances in polymers for anti-biofouling surfaces," Journal of Materials Chemistry, vol. 18, no. 29, pp. 3405-3413, 2008.

[62] A. S. Carlini, L. Adamiak, and N. C. Gianneschi, "Biosynthetic polymers as functional materials," Macromolecules, vol. 49, no. 12, pp. 4379-4394, 2016.

[63] D. Park, J. A. Finlay, R. J. Ward et al., “Antimicrobial behavior of semifluorinated-quaternized triblock copolymers against airborne and marine microorganisms," ACS Applied Materials \& Interfaces, vol. 2, no. 3, pp. 703-711, 2010.

[64] R. Henderson, S. A. Parsons, and B. Jefferson, "The impact of algal properties and pre-oxidation on solid-liquid separation of algae," Water Research, vol. 42, no. 8-9, pp. 1827-1845, 2008. 